\title{
Standing With Nature
}

W hen considering the relationship between nature and a particular culture, what might be wrong with that relationship and how it might be improved, one of the most basic and straightforward questions we can ask is exactly who negotiates the relationship-or more exactly what kinds of relationship can be negotiated by individuals on the one hand or by people acting as a group - the human community-or the other?

This is a question that seems so obvious it hardly seems worth asking. Yet it is a question that raises some real issues about our own society and its history-issues that I suspect have a great deal to do with our various environmental problems.

A distinctive feature of American society is a strong emphasis on individualism, and an explicit rejection of the rituals that have traditionally served to define and affirm community.

This is to some extent a legacy of the Puritanism of the founders of the early New England colonies and its rejection of various traditions associated with Anglicanism, and especially the Catholic Church, with its heavy emphasis on rituals and liturgies conducted by a consecrated priesthood as a way of affirming the community of the faithful and negotiating its relationship with God.

Horrified by abuses of both institutions, the Puritans replaced priests with ministers, demoted the sacraments to mere symbolic acts, and rejected the elaborate hierarchical structure of the Medieval Church.

The aim, in part, was to minimize the social machinery that had developed to negotiate the relationship with divinity-in effect to eliminate the middleman in order to clear the way for the individual to deal directly with his or her creator.

Implicit in this reaction was a radical individualism - the idea that it is ultimately the individual who confronts divinity and negotiates a relationship with it, and that the role of the community is properly a secondary, supporting role.

This tendency was reinforced by the weakening of the tradition of ritual, one function of which had been to support and define the community of worshippers. One result was a tendency toward separatism, even in some cases the spiritual isolation of the individual. The separatist Roger Williams, for example, defected from the Puritan congregation in Boston and eventually concluded that he could share communion, the fundamental ritual of community, only with his wife.
Mainstream Puritanism, of course, avoided such extremes. But the tendency toward separatism and isolation of the individual was inherent in Puritanism, as the Puritans themselves were well aware. The splintering of sects was inevitable, suggesting the possibility of the logical conclusion-a congregation of one.

This tradition - this complex of ideas about the "other" and our relationship with it-entered modern environmental thinking through the work of writers such as Emerson and Thoreau, who were both strongly influenced by Puritan tradition. This is clearly evident in their emphasis on individual self-reliance and in their skepticism about community and what Thoreau called its "filthy institutions."

Hence the pattern of withdrawal from society characteristic of this tradition. That congregation of one that had troubled the Puritan imagination is realized as Thoreau celebrating his solitary life at Walden Pond, and later by a succession of thinkers such as John Muir, Robert Frost, Aldo Leopold, Loren Eiseley, and Ed Abbey, all of whose search for communion with nature was an essentially personal, solitary one.

The experiences and writings of all these people affirm the value of the individual quest, but they also reveal its limitationslimitations that I believe underlie the failure of modern environmentalism to come to grips with the fundamental problem of the relationship between nature and culture.

These, I suggest, stem from the old puritan habit of spiritual self-reliance and its downplaying of the role of community and ritual in communion - whether with God or with nature. The limitations of this tradition are obvious from an ecological perspective. Human beings are essentially a social species. For such creatures, the solitary individual is actually an ecological non-entity, as helpless and as ecologically irrelevant as a solitary honeybee. For such creatures, the link to nature is necessarily mediated by the community. The solitary individual-King Lear's "unaccommodated man"-is cut off not only from the human, but from the larger community of plants and animals as well.

In the end, important as personal-and even solitary-experience may be, the relationship between humans and the rest of nature is essentially a relationship between communities, and it is the community, not the individual acting alone, that negotiates the terms of the relationship. To borrow a phrase from the lawyers, it is not the individual but the community that has standing with nature. 
When the community is weakened, in particular by the weakening of the ritual experience that defines and empowers it, its competence to negotiate this relationship is compromised, and its members are left without adequate means to achieve communion with nature. The result is a society alienated from nature- the real root of ecological catastrophe.

What has all this to do with the work and the experience of ecological restoration? Just this: if our relationship with nature must be mediated by the human community, our primary concern must be for the vitality of that community and the structures, traditions and dimensions of experience that sustain it. Hence the importance of ritual-not just the private rituals of personal development, but public rituals-liturgies, actually-that affirm and celebrate both the human community and its membership in the larger, biotic community.

Ritual traditions, however, must be built up out of actions and experiences that are themselves both communal and conventionalthat is, they must grow out of the shared work and experience of the community.

That the work of ecological restoration meets these criteria is evident from the experience of restorationists like the North Branch Prairie group in Chicago, the Bernal Hill volunteers in San Francisco, Bruce Handley's growing army of volunteers in central California, and the new volunteer-driven work in New York City's Central Park.

Though it can be carried out by individuals- that is one of its strengths-restoration can also be carried out by groups-and in general groups are needed to carry out high-quality restoration work on an environmentally significant scale.

Thus restoration projects tend to become community events. They carry participants not away from society, but back into it, and, through it, back into the natural community.

In this way they provide both the occasion and the scaffolding for the development of the new liturgy of communion with nature and the recovery of the ritual experience necessary to community, with its deep roots in the ancient world and in indigenous cultures.

William R. Jordan III

\section{Our New Look}

WU ith this issue we introduce a new design for $R \& M N$, intended to make the journal more attractive and easier to use. This is something we have been looking forward to for some time as part of a program for the general upgrading of the journal to keep pace with the growing needs of the restoration community.

The new design is the work of Madison designer Jane Tenenbaum, who worked closely with the editors and UW Press staff to create a format appropriate to our conception of $R \& M N$ as a publication that crosses disciplinary and class boundaries in an attempt to do justice to the craft of ecological restoration.

We hope you like the result as much as we do-and we'd appreciate any comments or suggestions you may have.

Coming up in future issues: "coached" notes, our first formally refereed articles, and more comprehensive coverage of the field of restoration and of restoration-related developments in other areas. 